DOI 10.37882/2223-2982.2020.04.05

\title{
ПРОБЛЕМА НЕБЫТИЯ В ФИЛОСОФИИ ПАРМЕНИДА И ГЕРАКЛИТА: МЕЖДУ НЕГАТИВНОЙ ТЕОЛОГИЕЙ И ФИЛОСОФСКОЙ АПОФАТИКОЙ
}

\section{THE PROBLEM OF NON-BEING IN THE PHILOSOPHY OF PARMENIDES AND HERACLITUS: BETWEEN NEGATIVE THEOLOGY AND PHILOSOPHICAL APOPHATICISM}

\section{A. Bogomolov}

Summary: The article is devoted to the problem of demarcation of philosophical apophaticism and negative theology in the philosophy of Heraclitus and Parmenides. Relativism and the problem of determining the name of the Original allow us to formulate a hypothesis about the presence of both negative theology and philosophical apophaticism in the philosophy of Heraclitus. In the poem of Parmenides, being is endowed with divine attributes. Some characteristics of being are given apophatically. The article substantiates the position that the subject of philosophical apophaticism is non-being, which is also defined apophatically. It is shown that, in contrast to the teachings of Heraclitus, in the philosophy of Parmenides, the difference between negative theology and philosophical apophaticism has a pronounced character. The importance of the antithetical nature of the teachings of the two philosophers for the formation of the problem of negativity in the history of Greek thought is emphasized.

Keywords: Parmenides, Heraclitus, non-being, negative theology, philosophical apophaticism

\author{
Богомолов Алексей Владимирович \\ К.ф.н., дочент, ФГБОУ ВО «Нижегородский \\ государственный педагогический университет имени \\ Козьмы Минина» \\ ensestens@mail.ru
}

Аннотация: Статья посвящена проблеме демаркации философской апофатики и негативной теологии в философии Гераклита и Парменида. Релятивизм и проблема определения имени Первоначала позволяют сформулировать гипотезу о наличии и философской апофатики, и негативной теологии в философии Гераклита. В поэме Парменида бытие наделяется божественными атрибутами. Некоторые характеристики бытия даны апофатически. 0босновывается положение о том, что предметом философской апофатики является небытие, также определяемое при помощи отрицательных суждений. Показано, что, в отличие от учения Гераклита, в философии Парменида различие негативной теологии и философской апофатики имеет выраженный характер. Подчеркивается значение антитетического характера учений двух философов для становления проблематики негативности в истории греческой мысли.

Ключевые слова: Парменид, Гераклит, небытие, негативная теология, философская апофатика роблема небытия и тематика негативности в целом - одно из актуальных направлений философского поиска. Сложность, многогранность данной проблематики позволяет говорить об интегративном характере вопросов, формирующих исследовательское поле [6; 7]. Вместе с тем традиционно особое значение имеют историко-философские исследования, имеющие целью экспликацию исходных для западноевропейской традиции смыслов актуальных проблем.

Начало вопрошаний о негативности в истории западной мысли - досократическая философия. Конституирующим элементом негативности в западноевропейской онтологии и эпистемологии является категория небытия. Разумеется, когда предполагаемая цель историкофилософского исследования - реконструкция представлений ранних греческих философов, то говорить о категориальном аппарате можно лишь условно. Но в истории досократической мысли небытие, по меньшей мере, формируется как проблема.

Первое аргументированное и последовательное обращение к небытию мы обнаруживаем в философии элеатов. Во всяком случае, эта точка зрения представляется убедительной и распространена в специальной литературе. Однако можно предполагать, что учение элеатов и, в частности, Парменида является своего рода ответом на релятивистские интенции воззрений Гераклита. Основанием для такого предположения служит известный фрагмент поэмы «О природе», где говорится о тех, «коими "быть" и "не быть" одним признаются и тем же // И не тем же» [5; с. 2]. Вне зависимости от того, понимается ли данный фрагмент как критика Гераклита, антитетический характер их воззрений прослеживается с очевидностью [12, р. 27]. И опять-таки в специальной литературе этому аспекту, вне всяких сомнений, также уделено 
достаточное внимание. Вместе с тем, менее очевидной для истории философии как науки представляется проблема расширения основания компаративистики учений Гераклита и Парменида. В рамках настоящей статьи мы обратимся к анализу апофатической проблематики в воззрениях двух мыслителей. Впрочем, указанное предметное поле также не являет собою нечто неизведанное - тематика негативности в досократической философии в целом разработана в достаточной степени, в связи с чем надлежит конкретизировать цель настоящего исследования. Для этого обозначим основные предпосылки, формирующие рассматриваемую проблему.

Итак, одним из аспектов негативности в истории мысли является вопрос о соотношении философской апофатики и негативной теологии. В специальной литературе необходимость подобного различения, безусловно, обозначена. На этом, в частности, акцентирует внимание А.В. Ахутин: «мы касаемся темы философского апофатизма, который следует отличать от апофатизма богословского и понимать конкретно, т. е. (1) внутри логического катафасиса мысли и (2) в исторической (культурной) определенности этого логического катафасиса. Плотин, Ник. Кузанский, И. Кант, М. Хайдеггер - вот некоторые философы, в разные эпохи философии...яснее других выявлявшие это апофатическое начало философии» [2, c. 49]. Здесь же отметим известную работу «Apophatisme et théologie négative», в которой автор, Р. Hadot, исходя из семантики слова ámóфабıс, устанавливает возможные различия в трактовках греческой негативности, а кроме того, обращает внимание на противоречия при обращении к понятию «негативная теология» [13].

Дефиниция различий философской апофатики и апофатической теологии, ввиду вполне очевидных причин, предполагает иной формат исследования, чем одна отдельно взятая статья. Поэтому здесь обозначим, одним из возможных смыслов различения названных понятий является указание на то, что философская апофатика имеет своим предметом апофатически определяемое нечто, которое не является трансцендентным первоначалом, абсолютом, но вместе с тем необходимо, чтобы определяемое понятие относилось к предметной области философского знания. И в рамках настоящей статьи мы обращаемся к теме различения философской апофатики и негативной теологии в воззрениях Гераклита и Парменида.

В работах по истории философии наличествует мнение, согласно которому обнаружение четкой линии демаркации между философией и теологией в античной философии едва ли возможно [8, с. 31]. Это положение, конечно, относится и к досократическому этапу. Но отметим, в нашем исследовании, во-первых, речь идет о негативности, представленной в двух ее наиболее очевидных проекциях - негативной теологии и философской апофатике. Во-вторых, мы не ставим целью проведение четкой «демаркационной линии», мы лишь полагаем, что в воззрениях Гераклита и Парменида наличествует проблематика негативности, которая представлена как раз в двух названных ипостасях - и в качестве философской апофатики, и в качестве негативной теологии.

Обратимся, прежде всего, к воззрениям Гераклита. Определяющим здесь является релятивизм мыслителя из Эфеса. Принцип непрерывного становления, текучести обусловливает наличие переходных состояний. Релятивистская онтология сама по себе предполагает имплицитное наличие негативности как конституирующего элемента. В самом деле, релятивизм обусловливает, в том числе, характеристику любой вещи как того, что она не есть - она не есть то, что тождественно своему предшествующему и последующему состояниям, следовательно, каждый момент времени она есть то, что отлично от самой себя В контексте сказанного диалектику бытия и небытия, которая присуща релятивистской онтологии, можно представить как диалектику апофатических и катафатических определений. Однако, позволяет ли подобная трактовка предполагать наличие именно философской апофатики в воззрениях мыслителя из Эфеса? Мы полагаем, релятивизм Гераклита обусловливает возможность конструирования негативных суждений, причем, пожалуй, это происходит впервые в истории греческой мысли. Но в явной форме философская апофатика здесь не представлена, да и, вероятно, не могла наличествовать на раннем этапе античной философии. Вместе с тем еще раз подчеркнем, что философия Гераклита, ввиду специфики, во-первых, релятивистской онтологии, во-вторых, учения о противоположностях, допускает апофатическую дефиницию понятий. Но ранее мы указывали, что философская апофатика обращена к понятиям, имеющим философский контекст. Здесь, конечно, встает вопрос о специфике ранней греческой мысли вообще и особенностях дошедших до нас фрагментов сочинений Гераклита, ибо мы говорим о ситуации становления, формирования категориального аппарата философии, а фрагменты, передающие учение мыслителя из Эфеса, изобилуют метафорами, что чрезвычайно осложняет попытку ответить на вопрос о наличии философско-апофатической проблематики. Впрочем, приведем одно свидетельство Аристотеля из «Метафизики» (1005 b): «не может, кто бы то ни было признавать, что одно и то же и существует, и не существует, как это, по мнению некоторых, утверждает Гераклит» [1, с. 124]. Акцентируем внимание на том, что данный фрагмент возможно прочитать и иначе - как указание на то, что, согласно Аристотелю, Гераклит, будто бы утверждал: бытие и небытие суть одно. Иными словами, речь идет не о существовании и несуществовании некоторого нечто, а о бытии и небытии как таковых. В этой связи следует предположить, что релятивизм философии Гераклита можно спроецировать на всеобщие категории, т.е. бытие и небытие как таковые. Следовательно, один из 
возможных способов осмысления бытия и небытия как таковых - апофатический.

Обратимся теперь к теологии мыслителя из Эфеса. Г.В. Хлебников отмечает: ранние греческие философы стремились не только познать мир и место человека в нем, но и бога, который в нем правит, и что одной из первых таких попыток и была теология Гераклита [11, с. 31]. Кроме того, в специальной литературе распространено мнение, согласно которому Логос, бог, огонь - тождественные понятия [14, р. 76]. Но само постулирование бытия божественного в воззрениях мыслителя из Эфеса для целей настоящей статьи не является определяющим. Здесь важно понять, можем ли мы говорить именно о негативной теологии, и если это возможно, то в каком контексте.

Согласно некоторым свидетельствам доксографии, Гераклит постулировал, что божественное ускользает от познания. Так, в сочинении Плутарха находим: «бог отличен от нас во всем - и в естестве, и в движении, и в искусстве, и в мощи, и потому нет ничего невероятного, если он творит то, чего мы творить не в силах, и питает замыслы, для нас непостижимые. Отличаясь от нас во всем, он более всего несходен с нами и превосходит нас своими деяниями. Однако многое из того, что касается божества, как сказано у Гераклита, ускользает от понимания по причине неверия» [9, с. 242]. Исходя, в частности, из этого фрагмента можно предположить следующее. Во-первых, возможность познаваемости или понимания божественного не исключается. Но, вовторых, понимание бога возможно при условии веры. В-третьих, разумеется, здесь нет никакого указания на апофатический путь познания бога. Впрочем, нет здесь и положительной его трактовки. Следовательно, бог отличен от имманентно сущего, превосходит его во всем, что, вероятно, осложняет процесс познания, но не делает его невозможным. Невозможность этого обусловлена лишь отсутствием веры.

Далее, вернемся к тому положению, согласно которому в теологии Гераклита есть несколько имен, которыми он обозначает бога. Это и «Огонь», и «Логос», «Зевс» и др. Причины множественного именования трансцендентного первоначала, как представляется на первый взгляд, очевидны. Прежде всего, это отсутствие сформировавшегося категориального аппарата у досократиков в целом, малое количество аутентичных фрагментов и т.д. Однако наличествуют и иные объяснения. Так, Р.В. Светлов отмечает: «множественность имен, которые дает своему Началу Гераклит (Логос, Огонь, «Одно», Зевс, Борьба и проч.), также подсказывает, что конечная его выразимость последовательным и непротиворечивым образом невозможна, - следовательно, и здесь присутствует нечто от апофатического духа» [10]. Иными словами, данный тезис вносит существенное дополнение к сказанному выше. А именно, что не только отсутствие сформировавшегося категориального аппарата или почти всегда находящаяся под сомнением доксография обусловливают множественность и, как следствие, неопределенность в именовании божественного первоначала у Гераклита. В качестве причины указывается и невозможность непротиворечивого выражения, а значит, и познания божественного. Однако это дополнение опять-таки не позволяет однозначно утверждать, что в воззрениях Гераклита наличествует апофатическая теология. Пожалуй, мы вправе лишь предположить, что в учении мыслителя из Эфеса присутствует апофатический контекст теологии без использования апофатического метода как такового.

Следующий шаг в развитии проблематики негативности в истории ранней греческой мысли - философия Парменида. Итак, поэма «О природе» начинается с пролога, где действующим лицом является богиня. Дике говорит с юношей и излагает ему некое истинное учение. В свою очередь, пусть и косвенно, это означает, что истина имеет божественное происхождение. В следующей части поэмы мы находим определяющее для всей онтологии Парменида суждение, согласно которому истинным следует признать, что существует только бытие, а небытия не существует [4, с. 295]. Следовательно, тезис о существовании бытия имеет теологическое основание. Далее, бытие у Парменида наделяется рядом важнейших характеристик - оно, к примеру, не рождено, не может погибнуть [3]. Здесь апофатический контекст выражен с очевидностью. Но ключевое значение в этом случае получает другой вопрос: можно ли «бытие» Парменида отнести к божественному, т.е. является бытие богом, подобно тому, как, к примеру, богом является Единое у неоплатоников? В самом деле, бытие наделено божественными атрибутами, при этом божественность бытия превосходит божественность традиционных богов [11, с. 60-61]. Следовательно, можно говорить о том, что в учении Парменида наличествует и негативная теология.

Данный вывод, впрочем, обусловливает наличие следующего затруднения. Если бытие признается богом, то это означает совпадение онтологии и теологии у Парменида, что, как представляется, аннигилирует попытки разделения философской апофатики и негативной теологии. В этой связи особый интерес вызывает обращение элеата к небытию. Богиня отрицает существование небытия как такового. При этом однозначно говорится, что утверждение существования небытия - это ложный путь [4, с. 295]. Соответственно, все те рассуждения о небытии, которые представлены в поэме, выходят за рамки теологии Парменида, исключаются из нее. Безусловно, это наше предположение может вызвать возражения, в той части, что небытие диалектически связано с бытием, а значит, исключать небытие из теологии элеата нельзя. Но, как представляется, контекст обращения к небытию 
в поэме именно таков - речь о де-онтологизации небытия. О том, что небытие не существует говорит сама богиня, а значит, оно лишено божественного логоса. Следовательно, проблематику, связанную с пониманием Парменидом небытия в поэме, можно отнести к философской, а не теологической проблематике.

Данный вывод сам по себе не дает нам еще возможности сделать заключение о наличии философской апофатики в поэме. Вместе с тем можно дедуцировать ее основания. Согласно тексту поэмы, небытие не только не существует. Помимо этого, его нельзя и помыслить, поскольку «мыслить - то же, что быть, можно лишь то говорить и мыслить, что есть; бытие ведь есть, а ничто не есть» [4, с. 296]. Следовательно, небытие в «О природе» является тем предметом, в отношении которого применяются апофатические суждения, причем мы обнаруживаем последовательное применение таких суждений при обращении к небытию. Сказанное позволяет нам заключить, что в воззрениях элеата наряду с негативной теологией наличествует и философская апофатика.

Таким образом, в рамках настоящей статьи мы обратились к проблеме различия философской апофатики и негативной теологии в воззрениях Гераклита и Парменида. Историко-философское исследование данного аспекта учений двух греческих мыслителей изначально сопряжено с чередой спорных моментов. Во-первых, исследуемая проблема не была и не могла быть сформирована в философско-теологическом дискурсе досократиков в целом. Во-вторых, очевидно, само различие философии и теологии в воззрениях ранних греческих мыслителей также не предполагает четких границ. В-третьих, это проблема определения самой философской апофатики в рамках греческой философии. Однако эти обстоятельства не могут быть достаточным аргументом для отказа от исследования поставленной проблемы.

Итак, релятивизм позволяет предполагать наличие философско-апофатического контекста, а проблема именования трансцендентного первоначала, позволяет сформировать гипотезу о негативном аспекте теологии в воззрениях Гераклита. Здесь еще раз заметим, что различение философской апофатики и негативной теологии в философии мыслителя из Эфеса имеет во многом именно гипотетический характер. Иными словами, здесь мы можем констатировать лишь начало этой проблематики, ее неявное, имплицитное, наличие. В философии Парменида данное различие читается с большей очевидностью. В поэме бытие имеет атрибуты божественного и определяется оно и катафатически, и апофатически, соответственно, можно говорить о наличии негативной теологии. Небытие является противоположностью бытию, оно лишено божественного логоса, ввиду чего проблематику небытия следует отнести к не-теологическому контексту воззрений элеата. При этом небытие также определяется апофатически - оно, в частности, и несуществующее, и непознаваемое. Следовательно, есть основания полагать, что учение Парменида о небытии является предметом философской апофатики. Антагонистический характер воззрений Гераклита и Парменида имеет еще один аспект, к которому не столь часто обращаются в специальных исследованиях. Проблема различения философской апофатики и негативной теологии в философии Гераклита только формируется. Ввиду релятивистских интенций уловить это различие можно, однако оно во многом оно будет иметь гипотетический характер. Философия Парменида противостоит релятивизму Гераклита. Один из способов преодоления релятивизма - разделение бытия и небытия, что, в свою очередь, является основанием для разделения философской апофатики и негативной теологии в воззрениях элеата. Несмотря на имеющиеся различия в воззрениях Гераклита и Парменида, взгляды обоих мыслителей, взятые в их диалектическом единстве, представляют собой чрезвычайно важный этап в формировании проблематики негативности в истории западноевропейской философии.

ЛИТЕРАТУРА

1. Аристотель. Метафизика. Сочинения в четырех томах. Т. 1. М.: «Мысль», 1976. - 550 с.

2. Ахутин А.В. Поворотные времена. СПб.: Наука, 2005. - 743 с.

3. Воробьев Д.В., Смирнова Е.В. Учение Ксенофана из Колофона и Парменида Элейского о временной и пространственной бесконечности // Вестник Мининского университета. - 2018. - Т. 6. - №4. - URL: https://vestnik.mininuniver.ru/jour/article/view/896/698. (Дата обращения: 20.02.2019)

4. Лебедев А.В. Фрагменты ранних греческих философов Часть І. От эпических космогоний до возникновения атомистики. М.: Наука, 1989. - 576 с.

5. Маковельский А.О. Досократики. Часть вторая (элеатовский период). Казань: Издание книжного магазина М.А. Голубева, 1915. - 243 с.

6. Ничто / под ред. Д. Уэбба; пер. с англ. А. Капанадзе. М.: Лаборатория знаний, 2016. - 237 с.

7. Онтология негативности: сборник научных трудов / отв. ред. Е. Г. Драгалина-Черная. М.: Канон+; РООИ «Реабилитация», 2015. - 376 с.

8. Оплетаева 0.Н. Истоки и смысл апофатической традиции. Философия и теология // Вестник адыгейского государственного университета. Серия 1: Регионоведение: философия, история, социология, юриспруденция, политология, культурология. 2010. № 4. С. 30-36.

9. Плутарх. Сравнительные жизнеописания. Т. 1. М.: Наука, 1994. - 702 с.

10. Светлов Р.В. Платонизм и происхождение «интеллектуализма» в понимании первоначала // URL: http://platoakademeia.ru/index.php/ru/academeia/ 
item/4-academeia_1-02 (дата обращения: 09.12.2019)

11. Хлебников Г.В. Античная философская теология. М.: ЛЕНАНД, 2014. - 312 с.

12. Drozdek A. Greek Philosophers as Theologians: the divine arche. Ashgate Publishing Ltd., 2007. - 275 p.

13. Hadot P. Apophatisme et théologie négative // Exercices spirituels et philosophie antique. Paris. Études augustiniennes, 1987. Pp. 185-193.

14. Naddaf G. Revisiting the Religion of the Early Greek Philosophers, and Socrates' Contribution to the Controversy. Ápeiron. Estudios de filosofía. 2019. № 11. Pp. 65-97.

(с Богомолов Алексей Владимирович (ensestens@mail.ru)

Журнал «Современная наука: актуальные проблемы теории и практики»

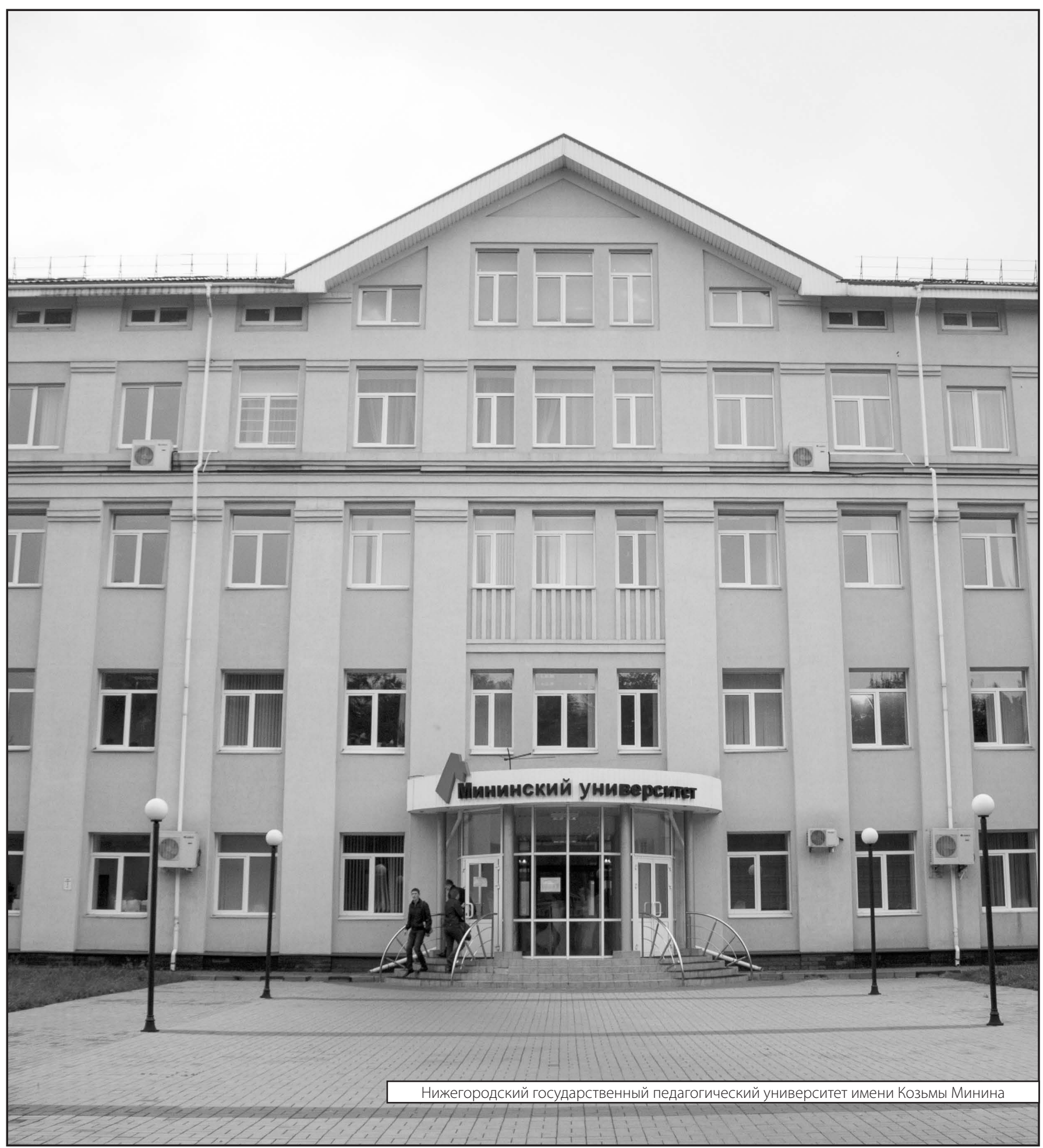

